\title{
CrimRxiv
}

\section{A new Geographic Profiling Suspect Mapping And Ranking Technique for crime investigations: GP- SMART}

Sophie Curtis-Ham, Wim Bernasco, Oleg N. Medvedev, Devon L. L. Polaschek

Published on: Mar 01, 2022

DOI: $10.21428 / \mathrm{cb} 6 \mathrm{ab} 371.5 \mathrm{ff} 24736$

License: Creative Commons Attribution 4.0 International License (CC-BY 4.0). 
